Basrah Journal Of Surgery
Case Report

Bas J Surg, December, 23, 2017

\title{
TEMPORAL BONE PATHOLOGY, A REPORT OF THREE CASES
}

\section{Isam M Al-Shareda}

MBChB, FICMS, Assist. Prof. of Otolaryngology, Dept. of Surgery, College of Medicine, Basrah University, Basrah, IRAQ.

\begin{abstract}
Temporal bone can be affected by different conditions. In our area, the most common disease conditions of the temporal bone are fibrous dysplasia, histiocytosis $X$ and squamous cell carcinoma.

This is a report of three females who have temporal bone disease conditions. They have poor clinical symptomatology. Since the incidence of malignancy is rare so differentiation between chronic inflammation and tumors is difficult and a biopsy is a must.

Computed tomography (CT) was the diagnostic aid of choice which also was very helpful for follow-up to assess the disease progression, while Magnetic resonance imaging (MRI) was useful to identify intracranial extension. Treatment of these conditions included surgery, radiotherapy and chemotherapy.
\end{abstract}

\section{Introduction}

耳ibrous dysplasia is a tumour-like Clesion of the bone ${ }^{1}$. It is self-limiting, not encapsulated and is characterized by replacement of normal bone with cellular fibrous connective tissue and is of unknown etiology ${ }^{2}$. The disease may develop at early age, and progress actively during childhood and stabilize in adulthood $^{3}$. This disease is much more frequent in white populations than black ${ }^{1}$ and the monostotic form is found more often in females than in males. In onethird of the cases, it is located in the maxilla or mandible and sometimes the frontal or sphenoid sinus are obliterated by the disease $\mathrm{e}^{4}$.

Eosinophilic granuloma is an uncommon, benign disease described by uncontrolled expansion of Langerhans cells. The most successive destinations of inclusion are the skull, spine, ribs, femur, and pelvis ${ }^{5-7}$. Lichtenstein assembled this infection range under the name histiocytosis $\mathrm{X}^{8}$. The " $\mathrm{X}$ " because the etiology was obscure.

It is a solitary condition, typically restricted to skeleton with great anticipation. Kids and youthful grownups are most ordinarily influenced. Male to female proportion is $2: 1^{9}$. In spite of the fact that the etiology is obscure, injury, genetic pattern, immune system mechanism, metabolic problems, and viral contaminations have all been suspected. Temporal bone contribution is moderately uncommon ${ }^{6,10-12}$. One of the announced disease clinical presentation is osteolytic type. Normally present manifestations incorporate otorrhoea, otalgia, dizziness and conductive hearing misfortune, polyps and granulations of the middle ear. Once in a while, facial nerve and vestibulocochlear nerve paralyses might be seen in addition to sensorineural hearing misfortune. These symptoms may cover the fundamental illness and postpone diagnosis until disappointment of symptomatic treatment administrations ${ }^{13-15}$.

Squamous cell carcinoma of the middle ear and temporal bone is an uncommon threat yet is related with significant dismalness and mortality, both attributable to the disorder forms themselves and the treatment modalities. Squamous cell carcinoma represents $60 \%$ to $80 \%$ of all this bone malignancies then basal cell carcinoma ${ }^{16}$. The disorder influence guys and females similarly, with an age scope of $34-85$ years $^{17}$. It is 
often contended that chronic otitis media is a chance factor for temporal bone threat, particularly squamous cell carcinoma $^{16}$. The early symptoms looks like those of chronic suppurative otitis media, including purulent putrid otorrhoea, extreme otalgia, bleeding, and pruritus. Since the rate of disease is uncommon, separating between chronically draining ear with related inflammation and a malignancy is typically troublesome. Other exhibiting clinical features of malignancy incorporate hearing misfortune, headache, tinnitus, vertigo, and aural stuffing. Cranial nerve paralyses may happen. Spread into the glenoid fossa can bring about trismus, dural involvement and deliver extreme torment and headache ${ }^{16}$.

\section{Case one:}

An 8 years old female patient, accidentally discovered mass behind the right ear which causing narrowing of the external auditory canal. On examination, the mass was originated from post auricular area and spreading to squamous and mastoid parts of temporal bone with limited extension to petromastoid area.

Few weeks later mastoidectomy was done and right mastoid bone mass was resected completely and sent for histopathology, the diagnosis was fibrous dysplasia of temporal bone. One year later the mass came back and another mastoidectomy was done. One year After a second mastoid resection the mass is again reoccurred but this time a watchful follow-up was chosen by a committee from otolaryngologists and neurosurgeons due to lacking of advanced facilities. A series of CT scans were taken for about 6 years. During this period the mass increases in size (figure 1) and extended to the occipital region. When the patient became 15 years old, she had repeated attacks of headache and craniotomy is decided (figure 2) .

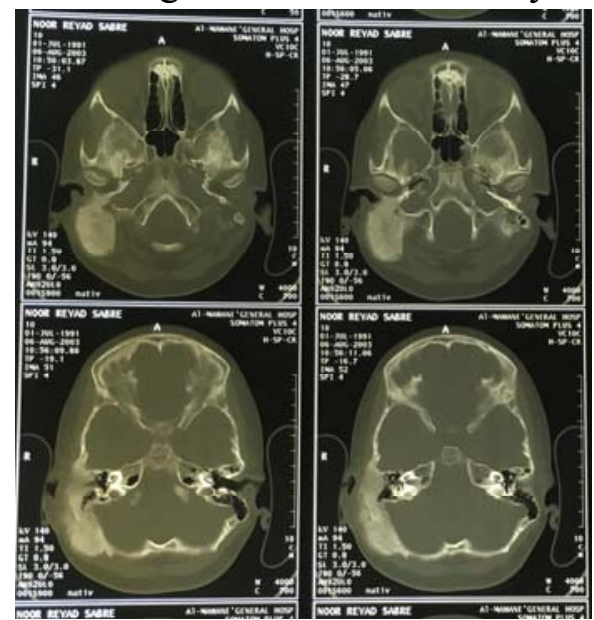

Figure 1: Extension of the disease after 2 mastoidectomies. This image was one of series imaging for follow-up which shows no intracranial invasion

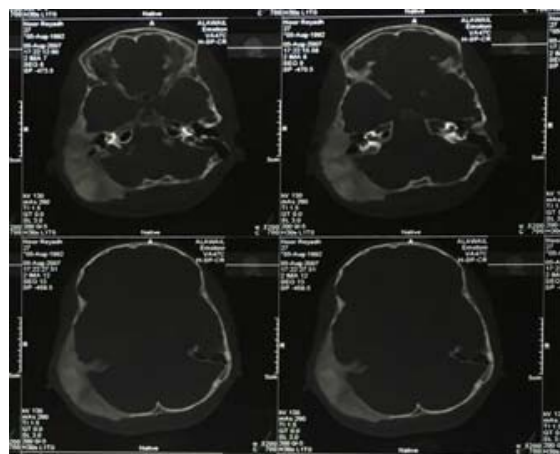

Figure 2: Pre-craniotomy when the patient was 15 years old 
She had craniotomy and cranioplasty with bone cement in Tehran, Iran(fig.3). There was no full intraoperative details about findings, but she developed partial facial nerve palsy which lasts few months until functions returns normal. Few months later she developed postaural discharging sinus which is healed and reoccurred multiple times after treatment. Three years later the sinus remains discharging and the patient had some feeling of instability in her operated side of skull.

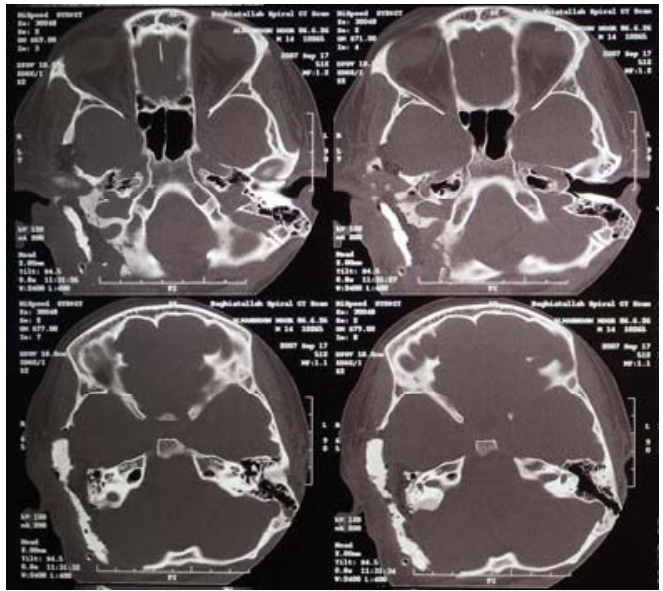

Figure 3: Postoperative, craniotomy and cranioplasty with bone cement

When the patient became 18 years old, another craniotomy was done in India, in which inferior part of cranioplasty was found infected with granulation tissue, a fistula was found leading up to external auditory canal (EAC) with normal tympanic membrane (fig.4). Cranioplasty implant was removed. There was a removal of the epithelium of EAC, tympanic membrane and remnant of malleus which was the only ossicle found. The Eustachian orifice was blocked with mucosa and fat.

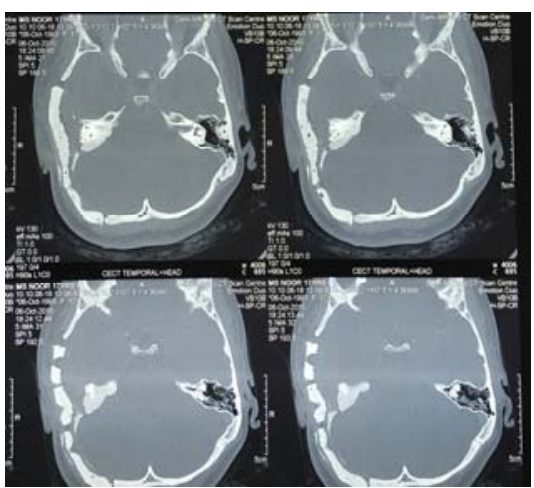

Figure 4. Preoperative revision craniotomy shows instability of the previous bone cement fragments.

After 9 months a second cranioplasty was done using Midpore implant with clearing of middle ear cleft. Till now, after 6 years from the last operation, the patient condition is stable with no mass and live a healthy life and she have a beautiful two years old daughter.

\section{Case two :}

The condition started as bilateral ear discharge when a female patient was 2 years old. The discharge was foul white to green in color and was associated with right sided aural polyps. Treatment lasts for about 8 months with no complete response. CT scan was done when the patient was 2 years old which shows bilateral temporal lesion in hematogenous soft tissue masses, on the right the dimension was $(44 \mathrm{~mm} \times 32 \mathrm{~mm})$ and on the left side was $(33 \mathrm{~mm} \times 23 \mathrm{~mm})$ with 
heterogenous enhancement after contrast injection. There was bony destruction of right mandibular ramus and both squamous and petrous parts of temporal bones. Also there was soft bony defect with irregular margins of upper petrous part of parietal bones with no intracranial extension or SOL as shown in figure 5.

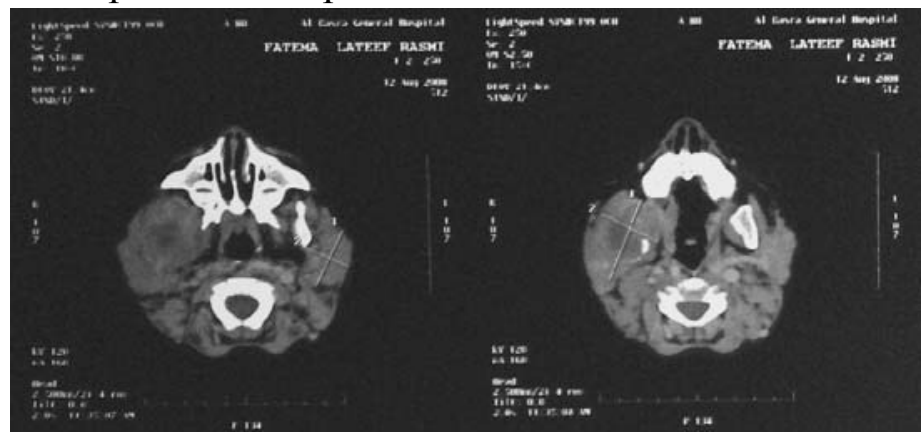

Figure 5: Bilateral soft tissue density with surrounding tissue destructions at time of diagnosis when the patient was 2 years old.

Biopsy was taken from external auditory meatus as multiple pieces of soft tissue and the report showed features of Langerhans cells histiocytosis $\mathrm{X}$ or eosinophil granuloma involving external auditory meatus. Patient received chemotherapy as vinblastine, pridnisolon, 6-mercapto purine and co-trimoxazole for two years. Few years later, the patient still had repeated right ear infection and mastoiditis so modified radical

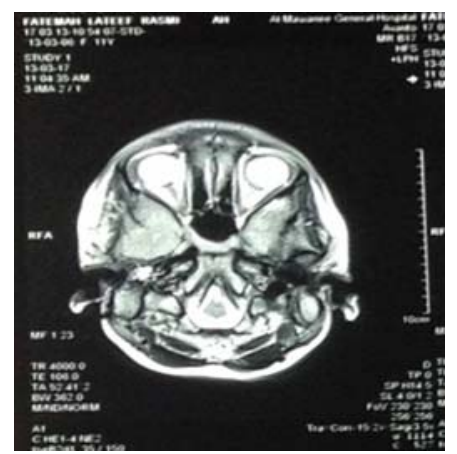

mastoidectomy was done with canal wall down and meatoplasty. Cholesteatoma present when the patient was 10 years old which when sent to histopathology study shows granulation tissue with no Langerhance cell histeocytosis.

Multiple imaging studies was done since then as CT (native and contrast) and brain MRI which shows complete resolution of the lesion, no mass but persistence mastoiditis at the right side (figure 6).

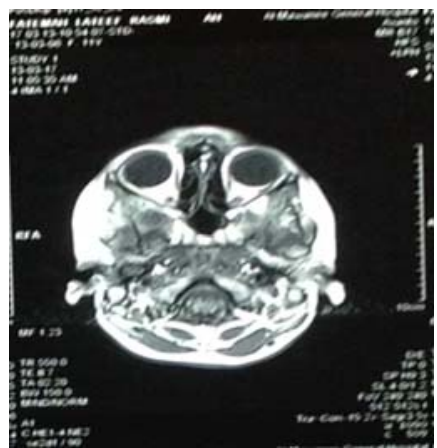

Figure 6: Recent MRI from serial follow-up imaging studies when the patient is 12 years old with no recurrence of the disease.

Now the patient is 12 years old, and still have mastoiditis with moderate CHL that affect her school performance, a hearing aid was prescribed to her.

\section{Case three:}

A 52 year old female presented with recent history of intense discharge from the right ear. She had history of intermittent recurrent right ear discharge for over 20 years as on \& off attacks especially after exposures to water or wet climate. The discharge is foul, yellowish to green in color comes one to two times per month. This was followed gradually by loss of hearing and the patient described it as dead. The case was diagnosed as chronic suppurative otitis media and treated as such for many years but with no response. She had severe headache which was gradually increased by time, it started 6 months before consultation with vertigo and severe otalgia. Her past history was inconclusive, apart from pulmonary $\mathrm{TB}$ 
10 years ago which has been treated by anti TB therapy. Otoscopic examination shows: Scanty discharge, sever retraction of tympanic membrane with invagination pocket at superior and inferior parts of TM with prominent middle folds, the attic cannot be visualized. Bilateral Rinne test was positive, Weber test is central. PTA:

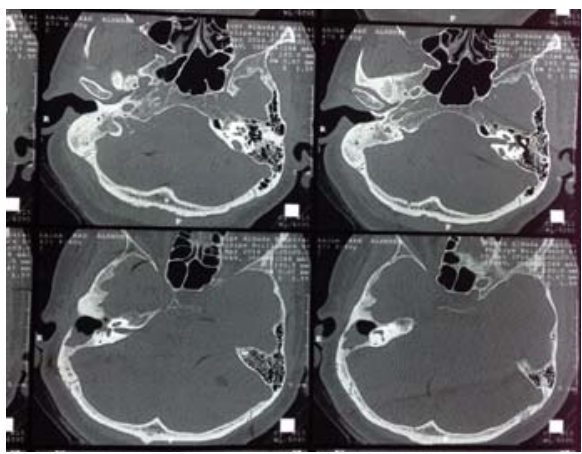

Right moderate mixed hearing loss. Left mild SNHL. Computerized tomography (CT) three months before surgery showed: Signs of obliteration of mastoid air cells and destruction of its wall with destruction of ossicles and blunting of scutum but intact tegmen tympani and normal inner ear as shown in figure 7 .

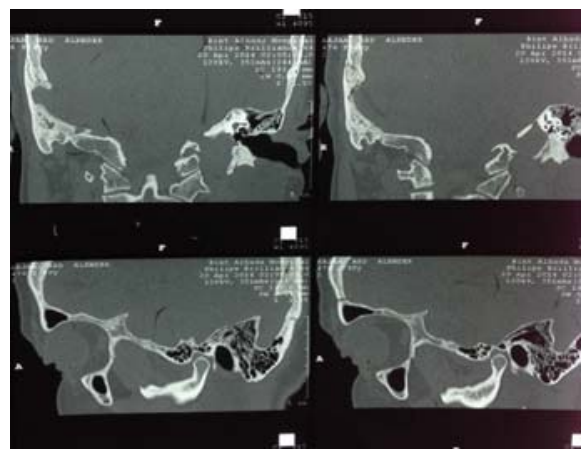

Figure 7: Computerized tomography three months before surgery

One week before operation, computerized tomography showed non pneumatized right mastoid air cells \& evidence of mastoid antrum bony

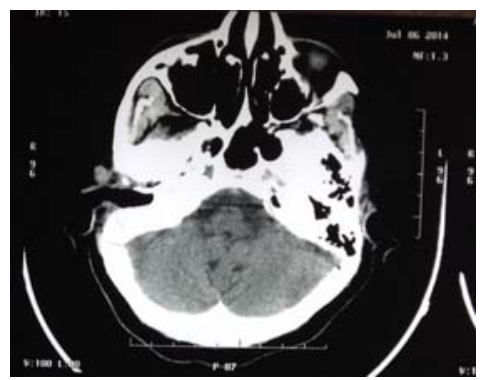

destruction. Middle ear cleft and ossicles cannot be visualized. The antral defect was occupied by soft tissue density as shown in figure 8.

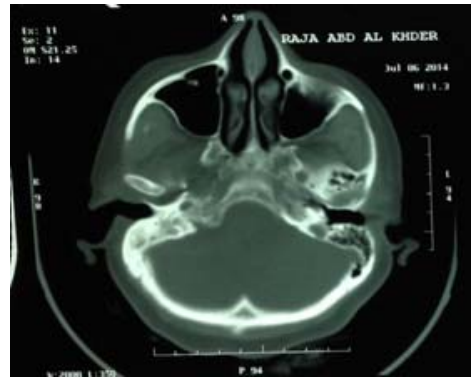

Figure 8: Computerized tomography one week before surgery

The patient had exploration of the right ear and radical mastoidectomy showed large mass eroded temporal bone, sigmoid sinus and dura. Biopsy was taken which revealed invasive well to moderately differentiated squamous cell carcinoma of mastoid cavity grade 1 and 2. She had uneventful post-operative period with no complications. Postoperative breast lump was noted but the patient said it is there for many years and had been referred to general surgeon who advised fine needle aspiration but she refused. One month post-operative brain

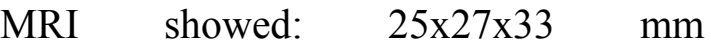
heterogeneous enhancing tissue in right petrous bone. The internal auditory canal, cochlea and semicircular canals appear intact, with no evident brain metastasis as shown in figure 9.

Figure 9: MRI Results

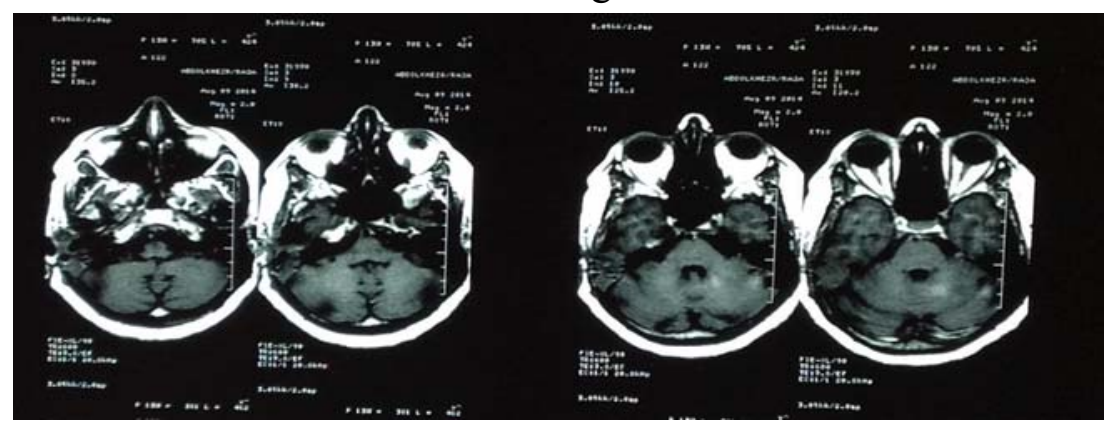


The patient had 30 radiotherapy sessions with six chemotherapy sessions in between. Now the patient condition is stable but there is some tinnitus and

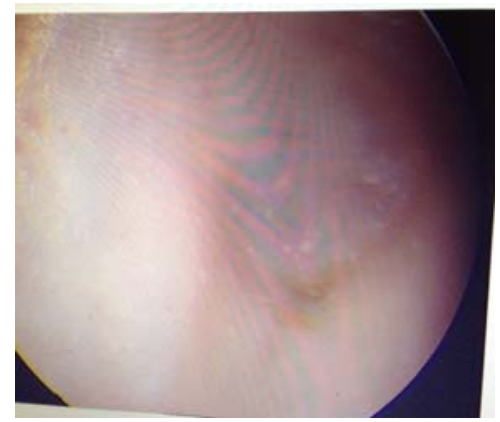

Figure 10: Otoscopic pictures

\section{Discussion}

The simple presence of fibrous dysplasia does not justify surgical intervention only if followed by significant clinical symptoms ${ }^{18}$. The indication for surgery of temporal bone fibrous dysplasia includes bone invasion of external auditory canal enough to produce conductive hearing loss, recurrent infections and secondary cholesteatoma. Surgical procedure aims at achieving 3 objectives: restoration of the function, prevention of complications, and case condition improvement. Radiotherapy should be avoided owing to high incidence of malignant transformation $^{19}$. Prognosis is good in most cases as in case one but it depends on the disease severity.

There are no particular signs or symptoms for Langerhans Cell Histiocytosis (LCH) including the skull, and the most widely recognized introduction is an agonizing and stable scalp mass which might be obvious in certain cases ${ }^{20,21}$. In the present investigation, the patient experienced bilateral ear discharge mainly from the right ear with no reaction to treatment.

In this way, imaging examinations were fundamental so as to find the condition which was situated in both temporal bones, and a wide hard defect was distinguished. As the greater part of LCH cases have skull contribution ${ }^{21}$, it was suitable to think that the lesion begun from the skull. Lately, positron emanation hearing difficulty in the operated on ear. Otoscopic pictures showed mastoid cavity 30 months after mastoidectomy (fig.10) and now she is on follow-up.

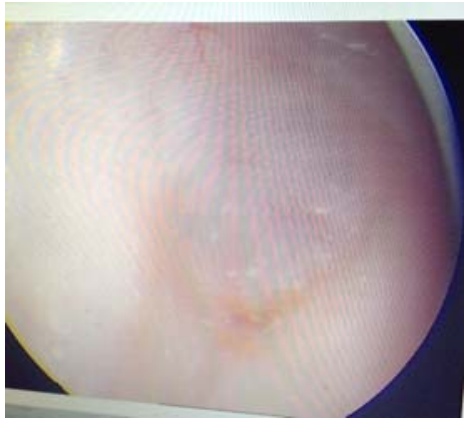

tomography-CT has ended up being the most delicate test accessible for recognizable proof of LCH lesions and in the assessment of patient reactions to therapy ${ }^{22,23}$. Once the finding of LCH has been affirmed, it is vital to evaluate the association of other organs, as $\mathrm{LCH}$ is normally a systemic condition.

In the present case, many general tests were performed, which affirm that no other organs were included. Due to the potential for improvement of sequelae, systemic treatment is suggested for the treatment of patients with lesions including the skull base, parietal and temporal bones ${ }^{24}$.

Thus, chemotherapy treatment was performed first in the present case which was therapeutic to her. There is as yet a debate $^{25-27}$ with respect to on the utilization of radiotherapy to treat $\mathrm{LCH}$ patients, this case got chemotherapy alone since radiotherapy was not accessible in the country at that time.

Temporal bone and middle ear squamous cell carcinoma is uncommon, however, is related with impressive morbidity and mortality, both due to the condition process itself and the treatment modalities.

Notwithstanding the diagnostic advances and treatment changes in this field, these malignancies still bear an awful prognosis. Squamous cell carcinoma represents above all temporal bone 
malignancies. It is habitually contended that chronic otitis media is a hazard factor for this bone cancer extraordinarily squamous cell carcinoma.

The early effects of carcinoma of temporal bone nearly resemble those of chronic suppurative otitis media, including purulent putrid otorrhoea, extreme otalgia, bleeding, and pruritus ${ }^{16}$ as in case three she was classically presented with chronic ear infection with headache and hearing loss and so radical mastoidectomy was done. The diagnosis was delayed because of the nonspecificity of symptoms for which she was dealt with as a case of chronic inflammation of the ear. The disease can be treated by, surgery or radiotherapy or a joined approach is still dubious as a conclusive study isn't yet done because the disease is rare. Surgeries classically incorporate sleeve resection, lateral temporal bone resection, subtotal or total resection of temporal bone. While a few investigators advocate total en bloc removal of the tumor, the others contend for piecemeal expulsion of gross tumor with protection of indispensable neurovascular structures took after by radiation therapy ${ }^{17}$. Mastoidectomy, resection of the lateral temporal bone and its subtotal resection are currently more appropriate ${ }^{28}$.

In a review investigation, radical radiotherapy was proposed as the treatment of choice for patients with beginningof squamous cell carcinoma of the outer auditory canal and middle ear ${ }^{29}$. Additionally, surgery, with negative surgical edges if conceivable, and radiotherapy was prescribed in this investigation as the standard care to cases of advanced stage.

The disparity in the studies itself shows that it is difficult to be certain about treatment results for mastoid squamous carcinoma from the literature.

As a rule, the treatment of temporal bone carcinoma comprises surgical extraction potentially followed by radiation.

The disease prognosis remains terribly bad owing to the late presentation which is far more worse in cases with facial nerve paralysis, positive tumor edges, dural inclusion, and local lymph nodes inclusion $^{16}$.

\section{References}

1. Hyams VJ, Batsakis JG, Michaelis L. Tumors of the upper respiratory tract and ear. Atlas of tumor pathology. Second series, Fascicle 25. Washington DC: Armed Forces Institute of Pathology, 1988.

2. Abdel-Wanis M, Tsuchiya H. Melatonin deficiency and f ibrous dysplasia: Might a relation exist? Medical Hypotheses. 2002; 59: 552.

3. Maran ASD, Lund V. Clinical rhinology. Stuttgart, New York: Thieme, 1990

4. Dominok GW, Knoch HG. Knochengeschwuelste und geschwulstaehnliche kochenerkrankungen, 3rd edn. Jena: VEB Gustav Fischer, 1982.

5.Cline MJ, Golde DW. A review and reevaluation of the histiocytic disorders. Am J Med 1973;55:49 60

6. Appling D, Jenkins HA, Patton GA. Eosinophilic granuloma in the temporal bone and skull. Otolaryngol Head Neck Surg 1983;91:358 65 .

. Cunningham MJ, Curtin HD, Butkiewicz BL. Histiocytosis X of the temporal bone: CT findings. J Comput Assist Tomogr 1988;12:70 4 .

8. Lichtenstein L. Histiocytosis X; integration of eosinophilic granuloma of bone, Letterer Siwe disease, and Schüller Christian disease as related manifestations of a single nosologic 8.tity. AMA Arch Pathol 1953;56:84 102.

.

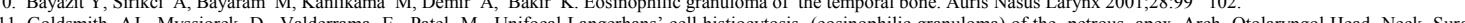
11. Goldsmith A

12. Akisada T, Harada T, Yoshihiro T, Kawai A. A case of bilateral eosinophilic granuloma in the temporal bone. Auris Nasus Larynx 1999:26:343 8 .

13. Kleinjung T, Woenckhause M, Bachthaler M, Wolff JEA, Wolf SR. Langerhans' Cell Histiocytosis with Bilateral Temporal Bone Involvement. Am J of Otolaryngol. 2003;24: 265-70

14. Marioni G, De Filippis C, Stramare R, Carli M, Staffieri A. Radiology in focus. Langerhans'cell histiocytosis: temporal bone involvement. J Laryngol Otol. 2001;115:839-41

15. Fernandez-latorre F, Menor-Serrano F, AlonsoCharterina S, Arenas-Jimenez J. Langerhans cell histiocytosis of the temporal bone in pediatric patients: imaging and follow-up. AJR Am J Roentgenol. 200;174: 217-21

16. Decker, B.C. (2003) Glasscock-Shambaugh Surgery of the Ear. Vol. 1, 5th Edition, PMPH-USA, 743-754

17. World Health Organization Pathology and Genetics of Head and Neck Tumours IARC WHO Classification of Tumours Series Vol. 9 of World Health Organization Classification

of Tumours. IARC Press, Lyon, 349,2005

18. Nager GT, Kennedy DW, Kopstein E. Fibrous dysplasia: a review of the disease and its manifestations in the temporal bone. Ann Otol Rhinol Laryngol Suppl 1982; $92: 1-52$.

19. Papadakis CE, Skoulakis CE, Prokopakis EP, Nikolidakis AA, Bizakis JG, Velegrakis GA, Helidonis ES. Fibrous dysplasia of the temporal bone: report of a case and a review of its

characteristics. Ear Nose Throat J 2000; 79(1):52-7.

20. Martini A, Aimoni C, Trevisani M and Marangoni P: Langerhans' cell histiocytosis: Report of a case with temporal localization. Int J Pediatr Otorhinolaryngol 55: 51-56, 2000. 21. Binning MJ and Brockmeyer DL: Novel multidisciplinary approach for treatment of langerhans cell histiocytosis of the skull base. Skull Base 18: 53-58, 2008.

22. Zhou W, Wu H, Han Y, Wang S, Dong Y and Wang Q: Preliminary study on the evaluation of Langerhans cell histiocytosis using F-18-fluoro-deoxy-glucose PET/CT. Chin Med J (Engl) 127: 2458-2462, 2014

23. Yamaki T, Kokubo Y, Saito Y, Matsuda K, Funiu H, Sakurada K, Sato S and Kayama T: A case of Langerhans cell histiocytosis of the skull in which preoperative methionine positron emission tomography was useful in comprehending the spreading of the lesion. Surg Neurol Int $5: 27,2014$

24. Haupt R, Minkov M, Astigarraga I, Schäfer E, Nanduri V, Jubran R, Egeler RM, Janka G, Micic D, Rodriguez-Galindo C, et al; Euro Histio Network: Langerhans cell histiocytosis (LCH): Guidelines for diagnosis, clinical work-up, and treatment for patients till the age of 18 years. Pediatr Blood Cancer 60: 175-184, 2013.

25. The French Langerhans' Cell Histiocytosis Study Group: A multicentre retrospective survey of Langerhans' cell histiocytosis: 348 cases observed between 1983 and 1993 . Arch Dis Child

75: 17-24, 1996.
26. Meyer A, Stark M, Karstens JH, Christiansen H and Bruns F: Langerhans cell histiocytosis of the cranial base: Is low-dose radiotherapy effective? Case Rep Oncol Med 2012:

27. Kriz J, Eich HT, Bruns F, Heyd R, Schäfer U, Haverkamp U, Büntzel J, Seegenschmiedt H and Micke O: Radiotherapy in langerhans cell histiocytosis - a rare indication in a rare disease. Radiat Oncol 8: 233, 2013 .

28. Prasad, S. and Janecka, I.P. (1994) Efficacy of Surgical Treatments for Squamous Cell Carcinoma of the Temporal Bone: A Literature Review. Otolaryngology-Head and Neck Surgery, 110, 270-280 http://dx doi.org/10.1016/S0194-5998(94)70769-3

29. Ogawa, K., Nakamura, K., Hatano, K., et al. (2007) Treatment and Prognosis of Squamous Cell Carcinoma of the External Auditory Canal and Middle Ear: A MultiInstitutional Retrospective Review of 87 Patients. International Journal of Radiation Oncology, Biology, Physics, 68, 1326-13. 